defect in intramitochondrial enzyme processing. Neurology Nov 1991; 41: $1815-1821)$.

COMMENT. In a review of the literature the authors found 26 additional cases of adult onset Reye's syndrome. Viral studies showed influenza $A$ or B in 11, varicella in 1, dengue in 1, and not reported in 14. 12 recovered.

The incidence of Reye's syndrome has decreased since 1981 and in 1988 there were only 20 cases reported. The relationship between Reye's syndrome and aspirin is debated (Casteels-Van Daele M. Lancet Nov 30, 1991; $\underline{338}: 1408)$ and the choice of alternative antipyretic management of fever is discussed in an editorial (Lancet Oct 26, 1991; 338:1049). Chronic paracetamol poisoning is reported in Australia and ibuprofen is suggested as an alternative.

\title{
CORTICOSTEROIDS IN PNEUMOCOCCAL MENINGITIS
}

The records of 97 infants and children with pneumococcal meningitis, 41 receiving corticosteroid therapy, were examined at the Department of Pediatrics, University of Texas Southwestern Medical Center, Dallas, Texas. When steroid-therapy was given before or concurrently with antibiotic therapy, none of 30 steroid-treated versus 16 of 52 non-steroid-treated patients developed neurologic or cardiovascular instability after the first parenteral antibiotic dose was given. Bilateral moderate or greater hearing loss occurred in $9 \%$ of steroid-treated group compared to $21 \%$ of non-steroid group. The incidence of hearing loss was significantly lower in those survivors of overwhelming meningeal infection who had been treated with steroids (Kennedy WA et al. The role of corticosteroid therapy in children with pneumococcal meningitis. AJDC Dec 1991; 145:1374-1378).

COMMENT. The data from this study were obtained retrospectively and a placebo-controlled double-blind study of dexamethasone in pneumococcal meningitis is indicated. The beneficial effect of corticosteroid adjunctive therapy has been demonstrated previously only in patients with Haemophilus meningitis. Since the incidence of $\mathrm{H}$. influenzae meningitis will be reduced by immunization in the future, S. pneumoniae or N. meningitidis will be the causal agent in a larger percentage of children (Schuster V, Kreth HW, N Engl J Med Dec 5, 1991; 325:1654). Dexamethasone in childhood meningitis is discussed in the correspondence section of this issue of The N Engl J Med. A retrospective evaluation of 12 years experience in the treatment of neonatal meningitis is reported from The Departments of Paediatrics and Bacteriology, Goteborg and Molndal, University of Goteborg, Sweden (Tessin I et al. Acta Paediatr Scand Oct 1991; 80:911-916). Initial treatment with ampicillin-aminoglycoside combination failed in 6 of 34 patients, despite organism sensitivity to the antibiotics. 